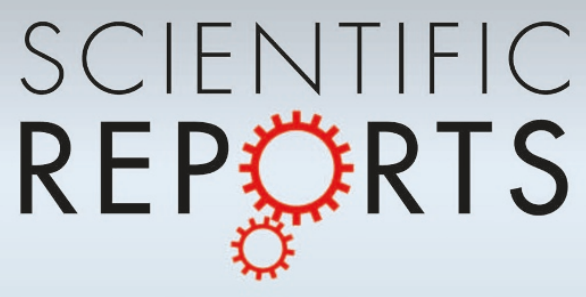

OPEN

SUBJECT AREAS:

CELL BIOLOGY

ENDOCRINOLOGY

CELL SIGNALLING

NEUROENDOCRINOLOGY

Received

8 June 2012

Accepted

24 August 2012

Published

25 September 2012

Correspondence and requests for materials should be addressed to

E.B.-M. (ebernal@ umich.edu)

\section{Importance of $\beta$-Catenin in glucose and energy homeostasis}

\author{
Lynda Elghazi, Aaron P. Gould, Aaron J. Weiss, Daniel J. Barker, John Callaghan, Darren Opland, \\ Martin Myers, Corentin Cras-Méneur \& Ernesto Bernal-Mizrachi
}

Department of Metabolism, Endocrine \& Diabetes, University of Michigan, Ann Arbor, MI.

In settings of increased insulin demand, failure to expand pancreatic $\beta$-cells mass leads to diabetes. Genome-wide scans of diabetic populations have uncovered several genes associated with susceptibility to type 2 diabetes and a number of them are part of the Wnt signaling. $\beta$-Catenin, a Wnt downstream effector participates in pancreatic development, however, little is known about its action in mature $\beta$-cells. Deletion of $\beta$-Catenin in Pdx1 pancreatic progenitors leads to a decreased $\beta$-cell mass and impaired glucose tolerance. Surprisingly, loss of $\beta$-catenin made these mice resistant to high fat diet because of their increased energy expenditure and insulin sensitivity due to hyperactivity. The complexity of this phenotype was also explained in part by ectopic expression of Cre recombinase in the hypothalamus. Our data implicates $\beta$-Catenin in the regulation of metabolism and energy homeostasis and suggest that Wnt signaling modulates the susceptibility to diabetes by acting on different tissues.

 ype 2 diabetes (T2D) is characterized by defective adaptation of $\beta$-cells to obesity-induced insulin resistance $^{1,2}$. Failure of $\beta$-cells to enhance insulin secretion and expand their mass in settings of increased insulin demand leads to hyperglycemia and (T2D). The signals responsible for $\beta$-cell expansion in conditions of insulin resistance are not well understood but growth factors, incretins, insulin and nutrients such as glucose and amino acids have been implicated. These extracellular signals regulate $\beta$-cells by inducing a number of pathways including PI3K/IRS/Akt, JAK/STAT, AMPK, PKC, and MAPK signaling among others. Uncovering novel signaling pathways involved in the regulation of $\beta$-cell mass and function is critical for understanding the susceptibility to the development of T2D.

The importance of $\beta$-cells in the pathogenesis of T2D has been underscored by the results of genome wide association studies ${ }^{3-5}$. These studies indicated that the majority of genes associated with increased susceptibility to $\mathrm{T} 2 \mathrm{D}$ are involved in the regulation of $\beta$-cell growth and function ${ }^{5-10}$. Interestingly, seven of these genes are components of the Wnt signaling pathway. In particular, variants of the transcription factor 7-like 2 (TCF7-L2) were shown to increase risk for T2D in different populations ${ }^{11-14}$. The significance of Wnt signaling in regulation of $\beta$-cell mass and function has been demonstrated recently ${ }^{10,15-18}$, however, the role of this signaling pathway in regulation of mature $\beta$-cells in vivo and the importance in modulation of whole body metabolism are poorly understood.

The canonical Wnt pathway modulates $\beta$-catenin activity by regulating its levels and cellular localization ${ }^{19,20}$. Activation of canonical Wnt signaling through binding of Wnt ligands to the Frizzled receptor induces a cascade of events that result in nuclear localization of $\beta$-catenin and activation of transcription by interacting with T cellspecific factor/lymphoid enhancer-binding factor (TCF/LEF) transcription factors ${ }^{21,22}$. $\beta$-catenin is a multifunctional intracellular protein that was originally identified as a cytoskeleton protein binding to the cytoplasmic domain of E-Cadherin and $\alpha$-catenin to maintain epithelial cell polarity ${ }^{21,23}$. In the absence of Wnt signaling the activation of a complex of proteins including Axins, GSK3 $\beta$ and APC induces proteasomal degradation of $\beta$ catenin $^{24}$. The importance of the Wnt signaling pathway during pancreatic development has been demonstrated in several studies ${ }^{1725-29}$. Over-expression of Wnt1 and Wnt5a in Pdx1-expressing pancreatic progenitors leads to pancreatic agenesis, suggesting that these proteins are important in the regulation of pancreatic cell fate ${ }^{30}$. Additional studies have employed different approaches to modulate Wnt signaling, and these have proven the important role this pathway plays in insulin secretion in vivo and in vitro ${ }^{16,31}$. Experiments in mice with gain and loss of $\beta$-catenin in Pdx1-expressing pancreatic progenitors have uncovered an essential role of $\beta$-catenin in the survival and growth of the exocrine pancreas during development and early post-natal stages ${ }^{26-29}$. Interestingly, these studies showed that loss of $\beta$-catenin does not affect pancreatic $\beta$-cell mass or glucose homeostasis $^{17,26}$. In contrast, activation of Wnt pathway by over-expressing an active mutant of $\beta$-catenin or 
Axin induces $\beta$-cell proliferation ${ }^{18}$. More recently, it was shown that deletion of $\beta$-catenin in mature $\beta$-cells using RIP-Cre mice had a detrimental impact on islet mass and function, leading to hyperglycemia in neonates ${ }^{25}$. The current experiments evaluate the role of $\beta$ catenin in adult $\beta$-cells as well as demonstrate the importance of the $\mathrm{Wnt} / \beta$-catenin pathway in whole body metabolism and energy homeostasis.

Pdx1, a homeobox transcription factor, is expressed during early pancreatic development and is essential for the formation of the pancreas $^{32}$. Pancreatic progenitors expressing $\mathrm{Pdx} 1$ give rise to endocrine, exocrine and ductal cells of the pancreas ${ }^{33}$. In the adult pancreas, $\mathrm{Pdx} 1$ expression is restricted to $\beta$-cells. To study the role of $\beta$ catenin in adult $\beta$-cells and its contribution to glucose homeostasis, we inactivated $\beta$-catenin using $\mathrm{Pdx} 1$-Cre mice $\left(\mathrm{Pdx}-\mathrm{Cre}^{\text {early }}\right)^{33}$. These mice exhibited glucose intolerance as a result of reduced $\beta$-cell mass and proliferation. Surprisingly, these mice also exhibited abnormalities in food intake, body size, motor activity, and had enhanced insulin sensitivity. These changes were ascribed to ectopic Cre expression in hypothalamic areas involved in regulation of food intake, activity, and metabolism. Our data support the concept that $\beta$-catenin/Wnt signaling regulates glucose homeostasis at different levels by altering the function of tissues involved in regulation of growth, energy expenditure, appetite and insulin secretion.

\section{Results}

Targeted deletion of $\boldsymbol{\beta}$-catenin in the pancreas. To confirm the effective deletion of $\beta$-catenin in the pancreas, we performed immunostaining for this protein in both $\mathrm{P} \beta$ cat-KO and control mice (Pdx1-Cre). Immunofluorescence for $\beta$-catenin revealed membrane staining in exocrine and endocrine cells from 3-month old control (Pdx1-Cre) mice (Figure 1A, B, E, F). In contrast, staining for $\beta$-catenin in the exocrine tissue of $\mathrm{P} \beta$ cat-KO mice displayed a mosaic pattern with areas of low expression (Figure 1C, D) combined with other exocrine areas in which $\beta$-catenin signal was completely absent (Figure 1G, H). These observations are consistent with prior reports demonstrating that some exocrine cells escape recombination and are able to repopulate ${ }^{17}$. More importantly, no staining for $\beta$-catenin could be observed in the pancreatic $\beta$-cells of $\mathrm{P} \beta$ cat-KO
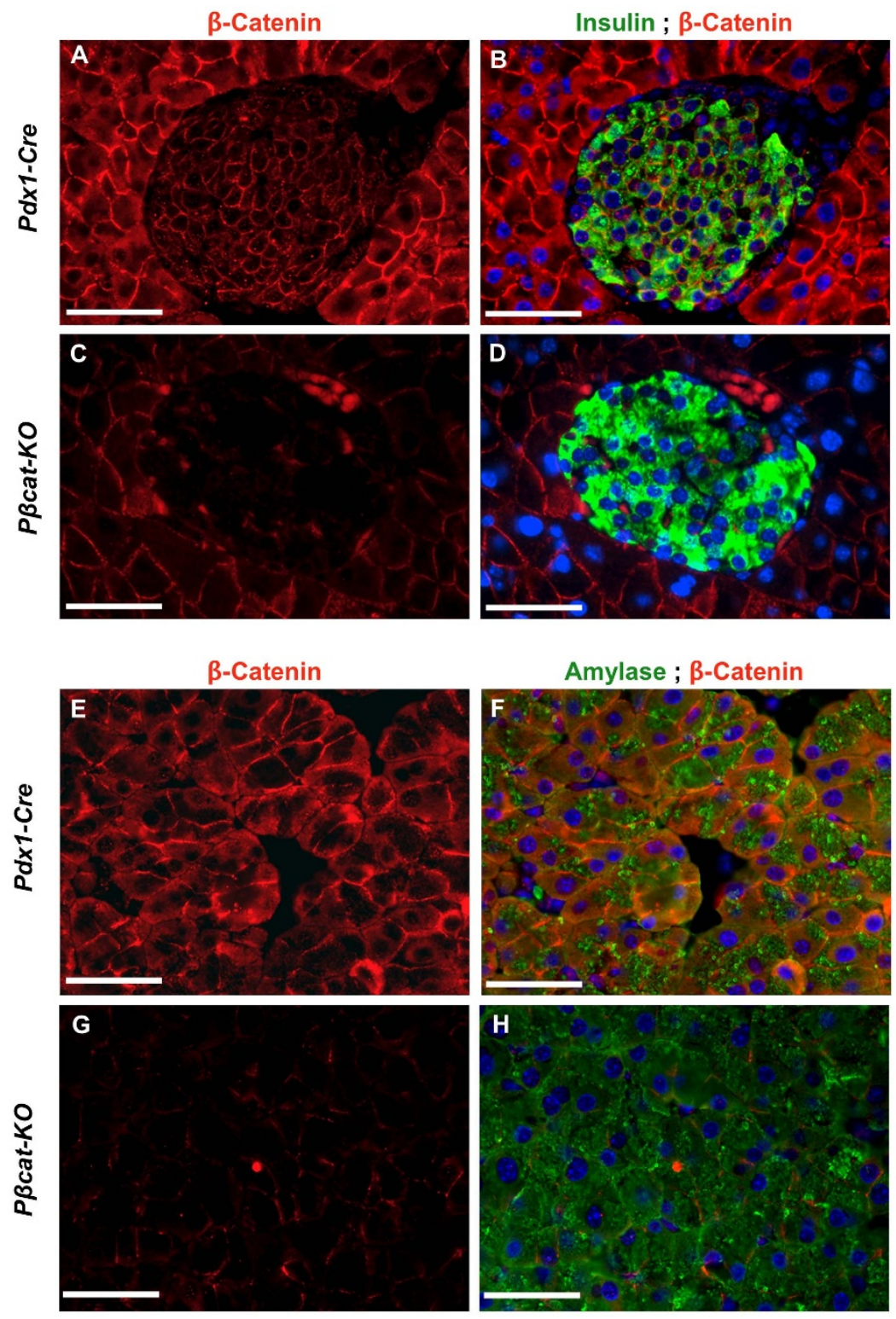

Figure $1 \mid$ Targeted deletion of $\boldsymbol{\beta}$-catenin in pancreatic progenitors. Immunofluorescence staining for $\beta$-catenin (red), Insulin or Amylase (green) in 3 month-old controls (A, B, E, F) and P $\beta$ cat-KO (C, D, G, H). Representative islets are shown in (A-D), and acinar tissue is shown in (E-H). Scale bars, $50 \mu \mathrm{m}$. 
animals (Figure 1C, D). Assessing the levels of $\beta$-catenin in islets by immunoblotting was unsuccessful due to difficulties isolating sufficient islet tissue in these mice.

Deletion of $\beta$-catenin in pancreatic progenitors results in impaired glucose metabolism. In order to assess the impact of the deletion of $\beta$ catenin in the islets on glucose homeostasis, fasting glucose levels and glucose tolerance tests were performed. $\mathrm{P} \beta \mathrm{cat}-\mathrm{KO}$ mice displayed higher fasting glucose levels at both 2 and 5 months of age compared to control animals (Figure $2 \mathrm{~A}$ and $\mathrm{B}$ ). After glucose injection, two-month old $\mathrm{P} \beta$ cat-KO male and female mice had significantly higher blood glucose levels at 60 minutes (Figure 2C and Supplemental
Figure 1A). Blood glucose levels after a glucose injection were higher at 30, 60 and 120 minutes in five-month old P $\beta$ cat-KO male and female mice indicating that the phenotype progressed with aging (Figure 2D and Supplemental Figure 1B). Similar glucose intolerance was observed in mice in which conditional deletion of $\beta$-catenin was obtained using two floxed alleles (Supplemental Figure 2A, B). These results suggest that the $\mathrm{P} \beta$ cat-KO mice have a decreased ability to dispose of the injected glucose. To determine whether these differences were associated with alterations in insulin secretory function, glucose-stimulated insulin secretion was evaluated next. Consistent with the high glucose levels, fasting insulin values were significantly reduced in $\mathrm{P} \beta$ cat-KO

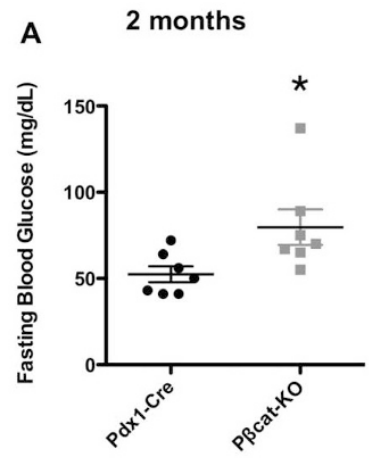

C
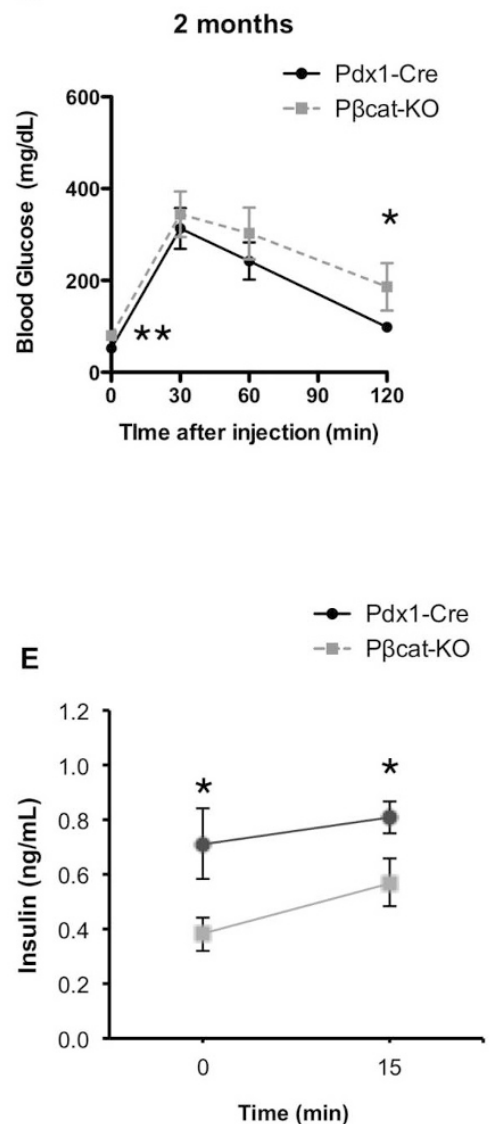

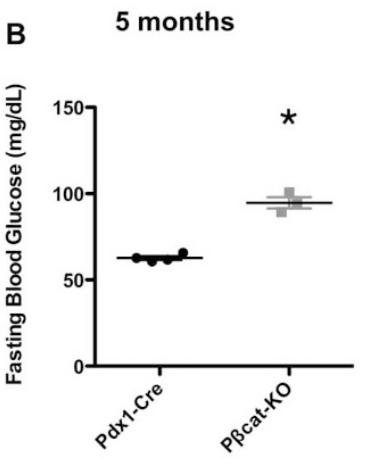

D
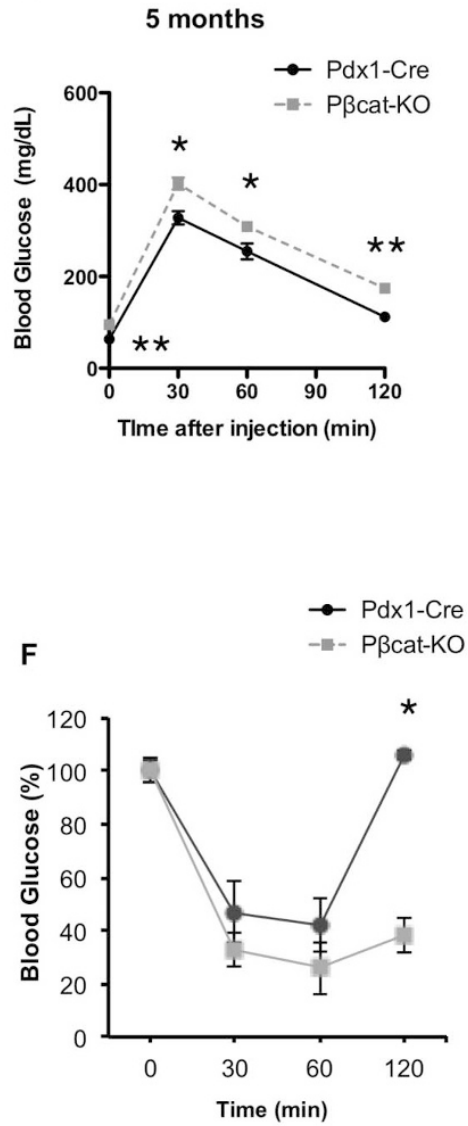

Figure $2 \mid$ Deletion of $\boldsymbol{\beta}$-catenin in pancreatic progenitors results in impaired glucose metabolism. Blood glucose levels measured after an overnight fast in Pdx1-Cre and P $\beta$ cat-KO at two (A) and five month of age (B) Intraperitoneal glucose tolerance tests were performed on Pdx1-Cre (black circles) and $\mathrm{P} \beta$ cat-KO (grey squares) in transgenic animals at $2(\mathrm{C})(\mathrm{n}=7)$ and $5(\mathrm{D})(\mathrm{n}=4)$ months of age using $(2 \mathrm{~g} / \mathrm{kg})$ of Dextrose after an overnight fast. (E) Insulin tolerance test (ITT) after $6 \mathrm{~h}$ fasting period $(n=4)$. (F) Serum insulin levels in $6 \mathrm{~h}$ fasted animals $(\mathrm{n}=4)$. Data are from males animals and presented as mean \pm SEM. $* \mathrm{p} \leq 0.05, * * \mathrm{p} \leq 0.005$. 
animals (Figure 2E) and remained lower than in controls 15 minutes after glucose injection (Figure 2E). Insulin sensitivity, assessed by insulin tolerance test, demonstrated that $\mathrm{P} \beta$ cat-KO mice had improved insulin sensitivity (Figure $2 \mathrm{~F}$ ). Taken together, these experiments demonstrated that $\mathrm{P} \beta$ cat-KO mice exhibit glucose intolerance, reduced insulin secretion but augmented insulin sensitivity. These results are consistent with the fact that the increase in insulin sensitivity observed in $\mathrm{P} \beta$ cat-KO animals protects these mice from developing a more severe impairment in glucose homeostasis.

Decreased $\beta$-cell mass due to reduced proliferation in $\beta$-catenindeficient animals. To determine if the alteration in glucose tolerance resulted from abnormalities in $\beta$-cell mass, we performed morphometric analysis of the pancreas. $\mathrm{P} \beta$ cat-KO animals exhibited a twofold decrease in pancreatic total weight (Figure 3A). Islet architecture
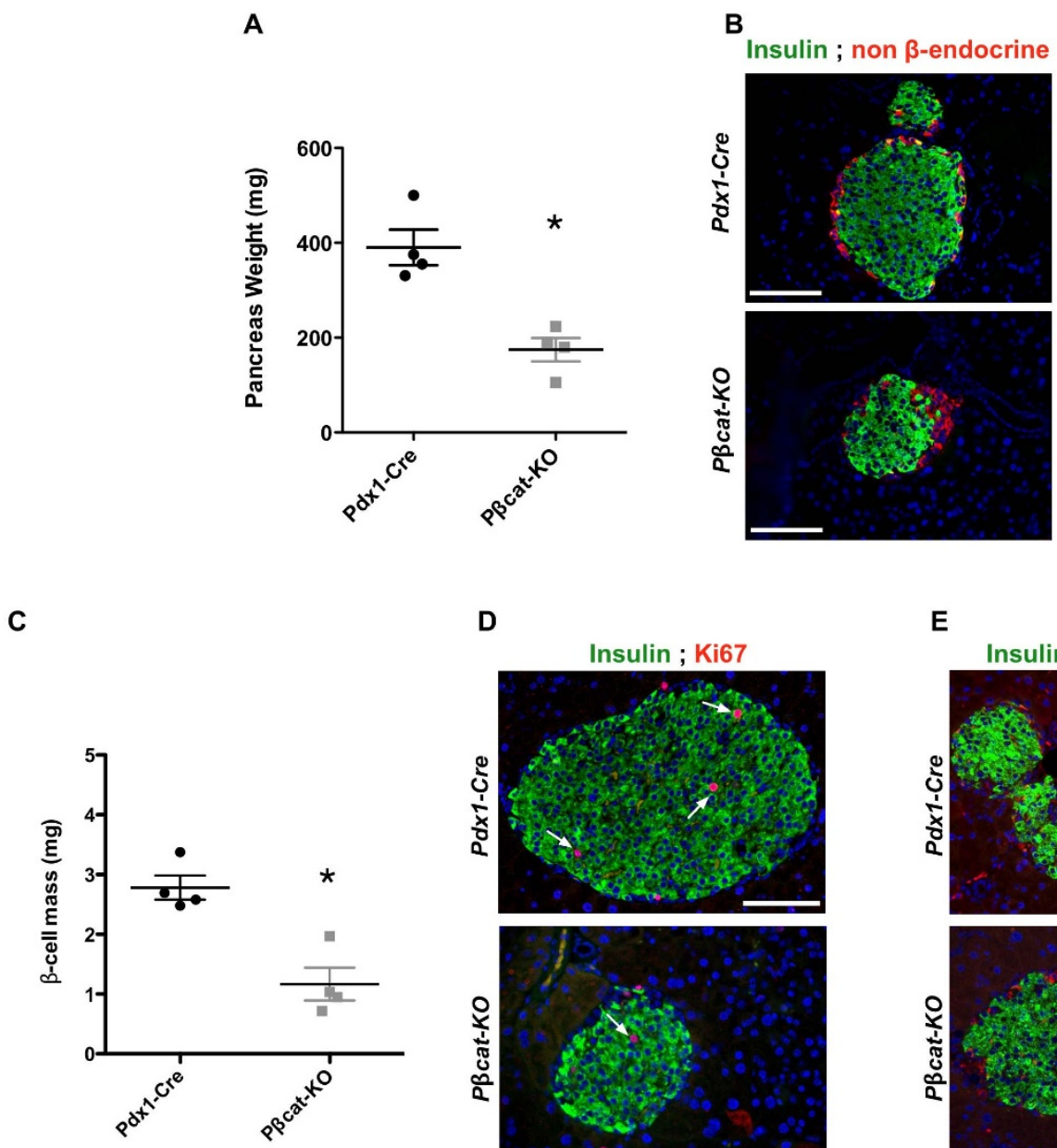

D
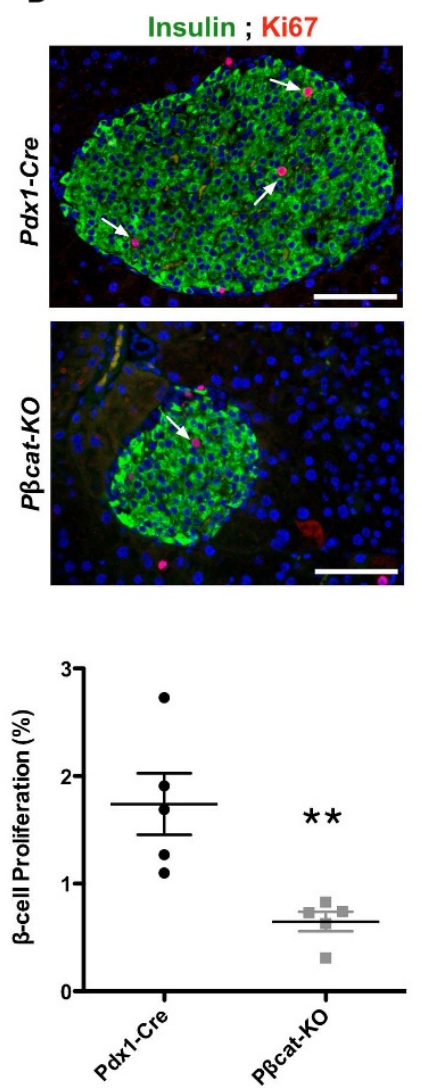

E
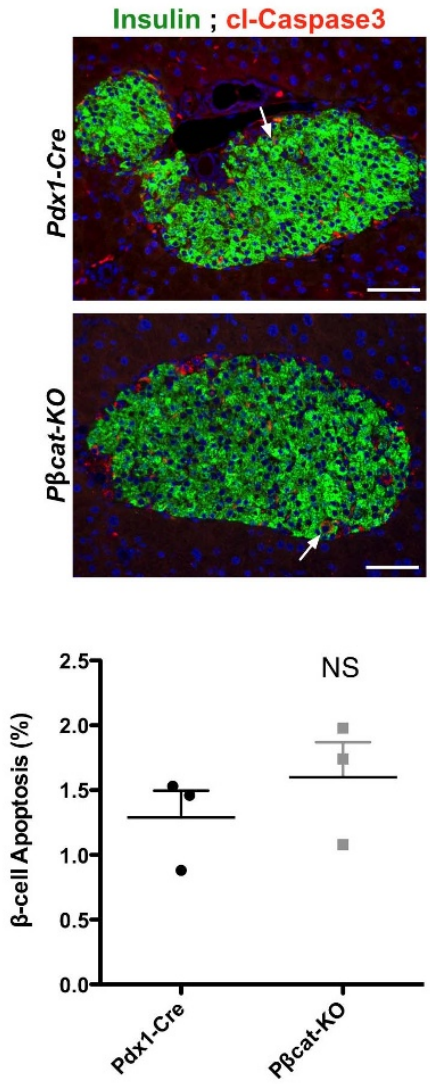

Figure $3 \mid$ Effect of absence of $\beta$-catenin in pancreatic progenitors on pancreas morphology. (A) Quantification of pancreatic weight in five month-old control and $\mathrm{P} \beta$ cat-KO mice. (B) Immunohistochemical detection of insulin (green) and non $\beta$-endocrine cells (glucagon, somatostatin and pancreatic polypeptide) (red) in pancreatic sections from five month-old Animals. (C) Quantification of pancreatic $\beta$-cell mass in five month-old control and $\mathrm{P} \beta$ catKO mice. (D) Immunofluorescence for insulin (green) and Ki67 (red) in pancreatic sections and quantification of $\beta$-cell proliferation (percentage of Ki67 positive $\beta$-cells/ $\beta$-cells counted). (E) Immunostaining for insulin (green) and cleaved caspase-3 (red) and quantification of the $\beta$-cell apoptosis (percentage of positive cleaved-caspase- $3 \beta$-cells $/ \beta$-cells counted). Data are presented as mean \pm SEM from at least 5 male mice per group. ${ }^{*} \mathrm{p} \leq 0.05$, ** $\mathrm{p} \leq 0.005$. Scale bars, $50 \mu \mathrm{m}$. 
determined by immunofluorescence staining for insulin and non- $\beta$ islet cells showed similar pattern between $\mathrm{P} \beta$ cat-KO and control mice (Figure $3 \mathrm{~B}$ ). However, islet morphometry analysis indicated that $\mathrm{P} \beta$ cat-KO mice had a decreased $\beta$-cell mass and the ratio of $\beta$-cell to acinar area was also reduced (Figure 3C and data not shown). The reduction in $\beta$-cell mass was still significant after normalizing the mass to the animal weight, which suggest that the abnormalities in exocrine tissue were not affecting these results (data not shown). In order to elucidate the mechanisms behind the reduction in mass, both proliferation and apoptosis were assessed in the $\beta$-cells by staining for Ki67 and cleaved Caspase- 3 respectively (\% of staining in insulin positive cells). Proliferation was decreased in $\mathrm{P} \beta$ cat-KO mice (Figure 3D) but the rate of apoptosis was not different between the two groups (Figure $3 \mathrm{E}$ ). These results suggest that the lower $\beta$-cell mass in $\mathrm{P} \beta$ cat-KO was due to a reduction in proliferation of the $\beta$-cells.

Conditional deletion of $\beta$-catenin in the pancreas results in impaired animal growth. In the course of the characterization of these mice we observed that the growth of $\mathrm{P} \beta$ cat-KO animals was impaired. At birth $\mathrm{P} \beta$ cat-KO pups appeared to have normal size but growth retardation developed during the first 8 weeks of life and was maintained up to 6 months of age in both males (Figure 4A) and females (Suppl. Figure 1C). A decreased in body length was also noted in 5 month-old P $\beta$ cat-KO mice (Figure 4B). To determine the mechanisms of growth retardation, we assessed food intake for 7 days. Interestingly, $\mathrm{P} \beta$ cat-KO mice showed higher food intake when compared to that of controls (Figure 4C). The decreased body weight could also result from alterations in food absorption related to the exocrine pancreas abnormalities or potentially digestive enzyme insufficiency. To assess this, we measured triglycerides, free fatty acids and cholesterol in the plasma and the stools. Plasma levels of these lipids were similar between $\mathrm{P} \beta$ cat-KO and the control mice (Figure 4D, E, F). Triglycerides and cholesterol content in the stools were also comparable, indicating that fat absorption was conserved (Figure 4G, H). Thus, mice with Pdx1mediated deletion of $\beta$-catenin are smaller and leaner but exhibit increased appetite when food intake was adjusted to their smaller body size.

Increase activity and energy expenditure in $\beta$-catenin deficient animals. Decreased weight in $\mathrm{P} \beta$ cat-KO mice could also be explained by increased activity and/or augmented basal metabolic rate. As early as one month of age, $\mathrm{P} \beta$ cat-KO mice exhibit a significant increase in motor activity. These animals appeared restlessness with hyperkinesia and exhibited occasional circling movements in both directions, ("spinning syndrome", see movie available online as Supplemental Material). Further characterization of the movement disorder showed that these animals presented defects in sensorimotor functions (strength and coordination) as well as vestibular-related dysfunction (data not shown). In order to measure the differences in activity and energy balance, 5month-old $\mathrm{P} \beta$ cat-KO and control animals were individually housed overnight in Oxymax cages. These studies revealed a significant increase in motor activity, oxygen consumption $\left(\mathrm{O}_{2}\right), \mathrm{CO}_{2}$ production and the respiratory quotient (RQ) in the $\mathrm{P} \beta$ cat-KO animals (Figure 5A-E). Therefore, these results suggest that the decreased weight and enhanced insulin sensitivity could be explained in part by increased motor activity.

Cre recombinase activity in Pdx1-Cre mice is observed in the brain. The hyperactivity and altered feeding behavior we observed in the $\beta$-catenin deficient animals are not typically observed with pancreatic-specific gene inactivation. We therefore hypothesized that some areas of the brain might be altered by ectopic expression of the Cre recombinase as has been recently demonstrated ${ }^{34}$. To test for ectopic expression of the Cre in the central nervous system, we crossed Pdx1-Cre mice with the Rosa-26R reporter line (Pdx1-Cre; $\mathrm{R} 26 \mathrm{R})^{35}$. The Cre-mediated recombination was then assessed by Xgal staining on sagittal sections of the hypothalamus. Pdx1-Cre; R26R mice revealed robust LacZ staining in the hypothalamus (Figure 6A). A more detailed description of our data demonstrating hypothalamic-mediated recombination in Pdx1-Cre mice was included in a recent publication ${ }^{34}$. In this publication, we showed that this Pdx1-Cre line exhibits Cre-mediated recombination in subpopulations of hypothalamic neurons involved in feeding behavior, energy expenditure and glucose metabolism ${ }^{34}$. These observations were further confirmed by immunohistochemistry using the $\beta$-galactosidase antibody on hypothalamic sections from Rosa26; Pdx1-Cre animals. As shown in Figure 6B, $\beta$-galactosidase immunostaining was indeed localized in the hypothalamus. These studies suggest that ectopic expression of the Cre recombinase in the hypothalamus could contribute in part to the abnormalities observed in energy homeostasis and feeding behavior.

及-catenin deficient animals are protected from high fat diet (HFD) induced obesity and insulin resistance. To study the capacity of adaptation of $\mathrm{P} \beta$ cat-KO mice to diet-induced obesity and insulin resistance, we subjected 8 week-old $\mathrm{P} \beta$ cat-KO and control animals to high fat diet (HFD) for a period of 20 weeks. Glucose tolerance test before HFD showed that P $\beta$ cat-KO animals exhibited higher blood glucose after 120 min of glucose injection (Figure 7A). As expected, control mice developed progressive glucose intolerance during the 20-week exposure to HFD (Figure 7B, C, D, E). In contrast, P $\beta$ cat$\mathrm{KO}$ animals exhibited better glucose tolerance after exposure to HFD indicating that these mice were resistant to HFD induced glucose intolerance (Figure 7B, C, D, E). To evaluate whether the response to incretins was altered by expression of the Cre recombinase driven by $\mathrm{Pdx} 1$ in the duodenum during the development, we performed oral glucose tolerance tests. The increases in glucose clearance in P $\beta$ cat$\mathrm{KO}$ mice following an oral glucose load suggested that the incretins response was properly maintained in $\mathrm{P} \beta$ cat-KO mice (Figure $7 \mathrm{~F}$ ). As anticipated from the limited weight gain observed in the $\mathrm{P} \beta \mathrm{cat}-\mathrm{KO}$ animals during HFD, they exhibited enhanced insulin sensitivity after 20 weeks of HFD compared to the controls (Figure 7G). Evaluation of islet morphometry at the end of the exposure to HFD showed that $\mathrm{P} \beta$ cat-KO displayed a reduction in $\beta$-cell mass compared to that of controls suggesting that enhanced insulin sensitivity played a major role in protecting $\beta$-cells from the detrimental effects of HFD (Figure 7H). Together, these results indicate that Pdx1-Cre-mediated deletion of $\beta$-catenin protects $\mathrm{P} \beta$ cat-KO mice from HFD-induced obesity and insulin resistance.

As expected, the control mice demonstrated significant weight gain during the 20 weeks of fat feeding (Figure 8A). In contrast, the weight gain in $\mathrm{P} \beta$ cat-KO mice was significantly reduced as these mice weighed $50 \%$ less than the controls at the end of the 20 weeks of fat feeding (Figure 8A). Analysis of body fat content using a dual energy X-ray absorptiometry (DEXA) scanner revealed that after 20 weeks of fat feeding, $\mathrm{P} \beta$ cat-KO animals exhibited significant decrease in total body fat in comparison to controls (Figure 8B). The body length of the animals was also shorter in the P $\beta$ cat-KO animals (Figure $8 \mathrm{C}$ ) but no changes in bone mineral density were observed (Figure 8C).

Considering the increased activity observed in $\mathrm{P} \beta$ cat-KO mice, we investigated the metabolic rate in unrestrained high-fat fed animals. Unrestrained $\mathrm{P} \beta$ cat-KO mice exhibited increase in oxygen consumption $\left(\mathrm{VO}_{2}\right), \mathrm{CO}_{2}$ production $\left(\mathrm{VCO}_{2}\right)$ and respiratory quotient (RQ) (Figure 8D-F). To test whether these differences resulted mainly from increased activity, the $\mathrm{P} \beta$ cat- $\mathrm{KO}$ and control mice were housed in cages where the space was reduced to limit their movement (restrained). As expected, $\mathrm{VO}_{2}, \mathrm{VCO}_{2}$ and RQ were significantly reduced in restrained control mice suggesting that the space 


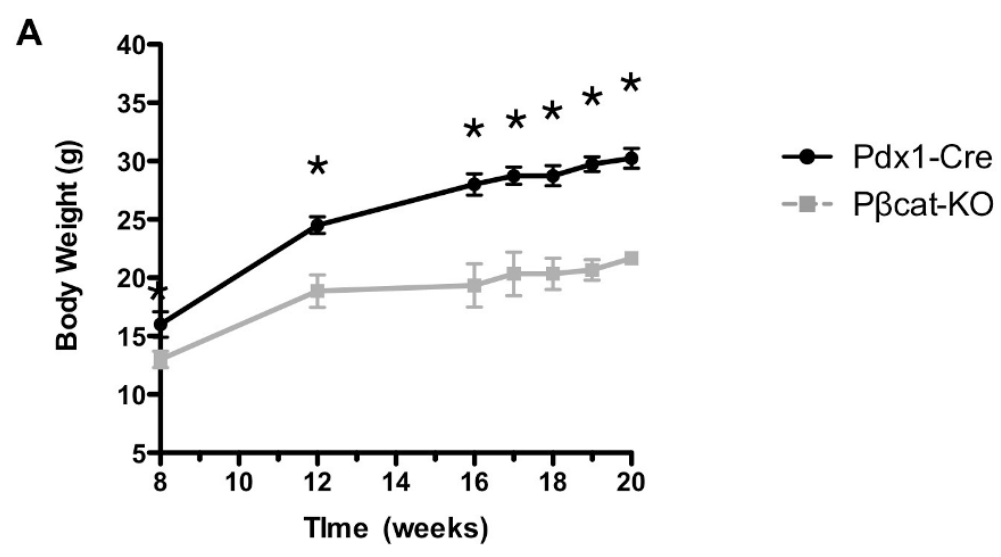

B

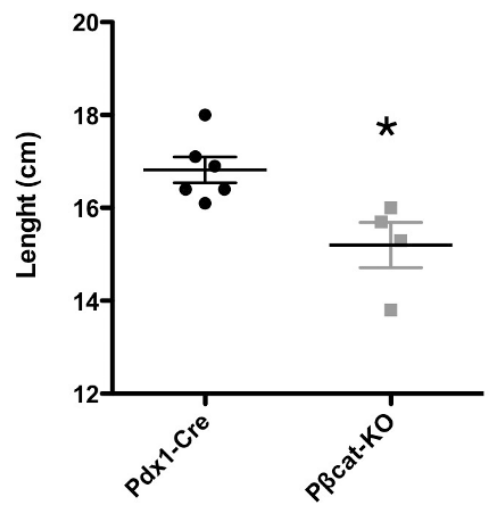

C

D

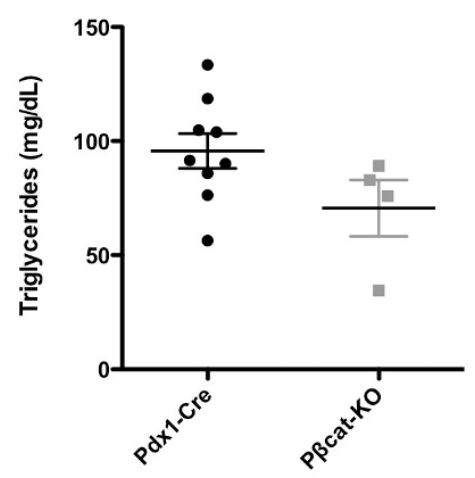

G

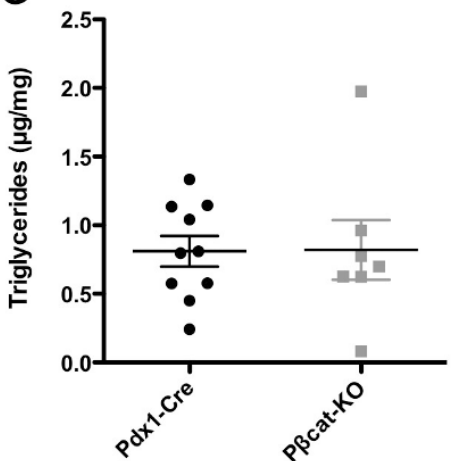

$\mathbf{E}$

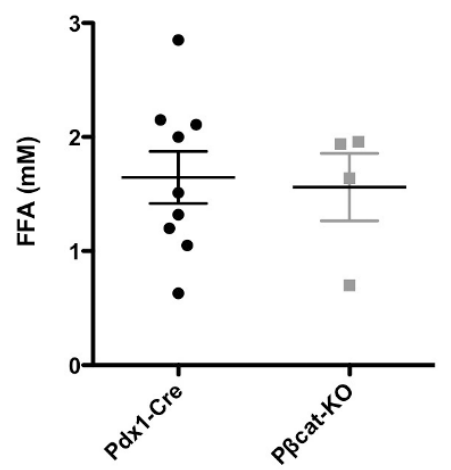

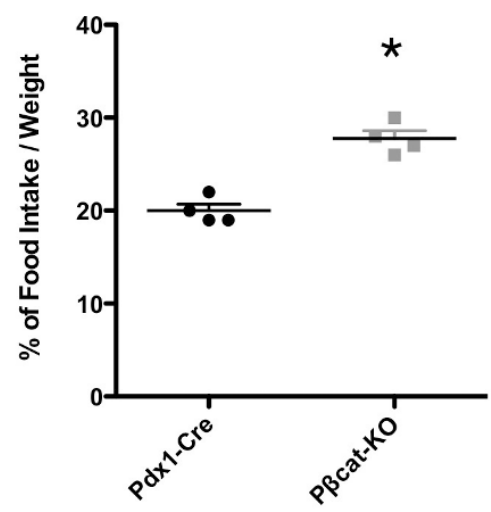

$\mathbf{F}$

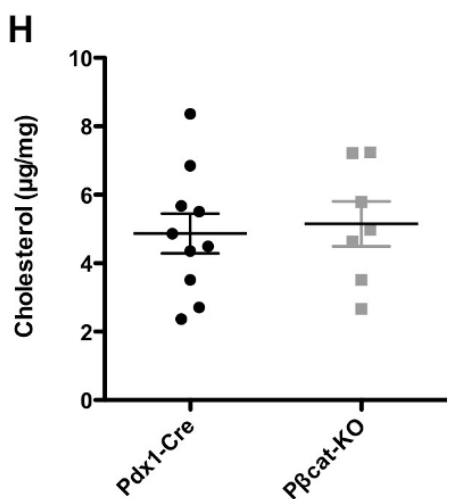

Figure $4 \mid \boldsymbol{\beta}$-catenin deficient animals are smaller, leaner and hyperphagic. (A) Body weights evolution of control (black line) and $\beta$-catenin-deleted (grey line) animals over 5 months period. (B) Body length was measured from nose to rump. (C) Food intake was measured once a day over a week period of time and normalized to body weight. Plasmatic levels of triglycerides (D), free fatty acid (E) and cholesterol (F) were measured after an overnight fast in Pdx1-Cre (black box) and P $\beta$ cat-KO (grey box). Triglycerides $(\mathrm{G})$ and cholesterol $(\mathrm{H})$ measured in the feces of the animals. Data are presented as mean \pm SEM from at least 7 males animals per group. ${ }^{*} \mathrm{p} \leq 0.05$. 
A

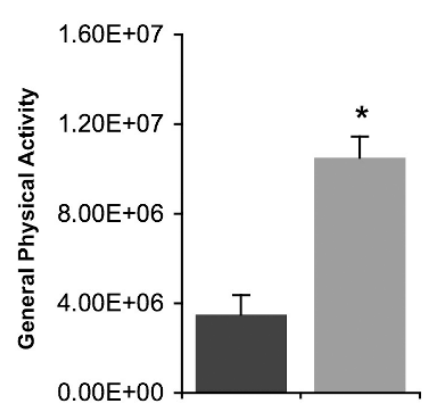

B

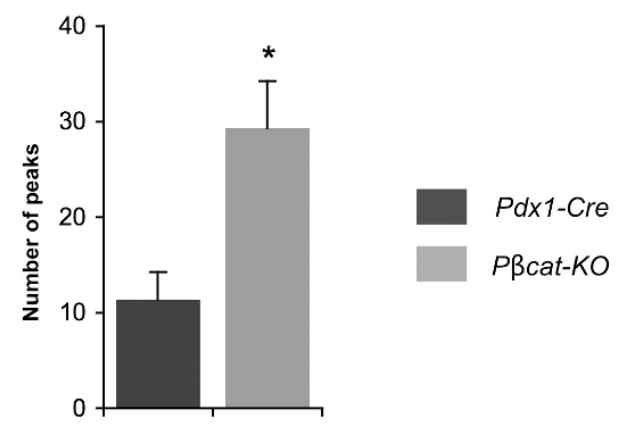

\section{C}

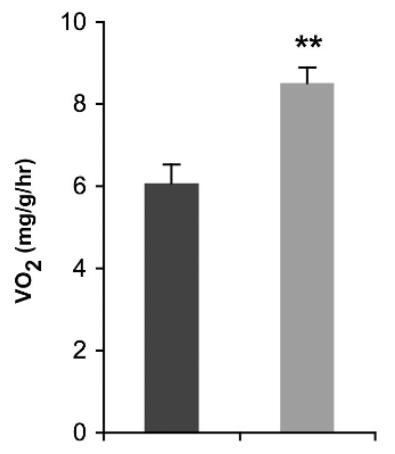

D

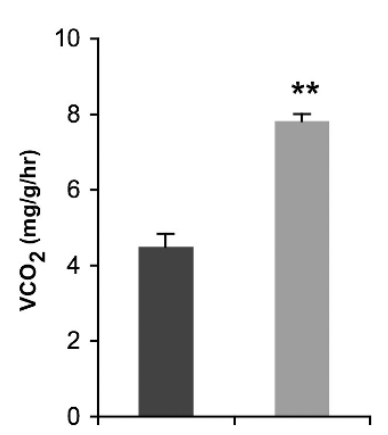

E

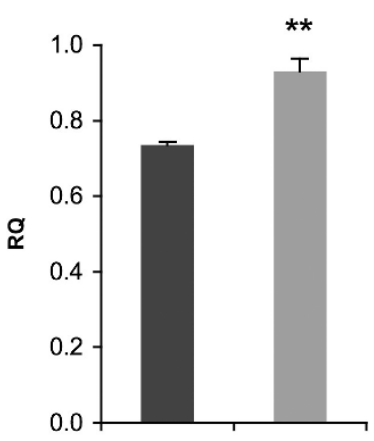

Figure $5 \mid$ Analysis of body energy balance. (A, B) General physical activity levels were measured over a 24 h period of time in control (black bars) and $\mathrm{P} \beta$ cat-KO (grey box) animals. $\mathrm{O}_{2}$ consumption (C) $\mathrm{CO}_{2}$ production (D) and respiratory quotient (RQ) (E) measured in the same group of animals over $24 \mathrm{~h}$ period of time. Data are presented as mean \pm SEM from at least 4 animals per group. ${ }^{*} \mathrm{p} \leq 0.05,{ }^{* *} \mathrm{p} \leq 0.005$.

reduction was effective (Figure $8 \mathrm{D}-\mathrm{F})$. In contrast, these parameters were not affected in restrained $\mathrm{P} \beta$ cat-KO mice (Figure $8 \mathrm{D}-\mathrm{F}$ ). These results indicate that $\mathrm{P} \beta$ cat-KO mice in both unrestrained and restrained conditions exhibited increased energy expenditure and metabolic rate and these changes could be explained in part by increased motor activity.

\section{Discussion}

These studies describe the phenotype of adult mice with Pdx1-Cre mediated deletion of $\beta$-catenin (P $\beta$ cat-KO). This work demonstrates that $\mathrm{P} \beta$ cat-KO mice exhibit abnormalities in glucose tolerance due to decreased $\beta$-cell proliferation and mass. These mice were glucose intolerant despite enhanced insulin sensitivity and hyperactivity. As a consequence of the hyperactivity, $\mathrm{P} \beta$ cat-KO mice were resistant to HFD induced obesity and insulin resistance. The abnormalities in glucose homeostasis and energy expenditure in these mice were explained in part by ectopic expression of Cre recombinase in areas of the brain that control appetite, growth and energy homeostasis. Moreover, these experiments underscore the importance of physical activity and neuronal regulation in the control of glucose homeostasis and suggest that $\beta$-catenin plays a major role in this process. Finally, these studies show that alterations in $\beta$-catenin/Wnt signaling can contribute to diabetes susceptibility not only by altering the rate of $\beta$ cell proliferation and total mass but also by regulating other tissues involved in control of appetite, energy expenditure and growth.

Recent experiments by other groups have explored the role of $\beta$ catenin in the pancreas with a focus on developmental stages and neonatal life $\mathrm{e}^{17,25,26,29}$. Deletion of $\beta$-catenin using the same Pdx1Cre ${ }^{\text {early }}$ mice line or Pdx1-Cre ${ }^{\text {late }}{ }^{36}$ demonstrated normal glucose tolerance and $\beta$-cell mass ${ }^{17,26}$. Here, we demonstrate that absence of $\beta$-catenin in mature $\beta$-cell impairs $\beta$-cell proliferation and mass and alters glucose homeostasis. Interestingly, glucose intolerance and $\beta$-cell mass defects were observed in spite of augmented insulin sensitivity, suggesting that the $\beta$-cell defect is very significant in these mice. The alterations in $\beta$-cell proliferation can be explained by decreased expression of Cyclin D1 and D2 as demonstrated by Rulifson et al. ${ }^{18}$ Unfortunately, the abnormalities in the exocrine pancreas made the islet isolation process difficult to obtain sufficient islet tissue to assess expression of cyclins and other proteins involved in the cell cycle. The differences between our glucose and $\beta$-cell mass phenotype and those of previously published studies could be explained in part by enhanced penetrant phenotype in our mice due to the inclusion of a deleted allele in the breeding strategy. Experiments in mice with conditional deletion of $\beta$-catenin using mice expressing inducible Cre recombinase under the control of the insulin promoter will be required to determine the role of this transcriptional regulator in mature $\beta$-cells.

The alteration in insulin sensitivity was one of the unexpected abnormalities observed after Pdx1-Cre mediated deletion of $\beta$-catenin. The cause of this improved insulin sensitivity is not entirely clear but it is likely that increased motor activity enhances insulin sensitivity in the basal state and prevents the development of insulin resistance induced by HFD. In fact, the increased motor activity leading to augmented insulin sensitivity in $\mathrm{P} \beta$ cat- $\mathrm{KO}$ mice was sufficient to protect $\beta$-cells from detrimental effects of HFD-induced obesity. This motor activity increase was not limited to spinning syndrome (see movie in Supplemental Material), as it was still present after restricting the cage space (Figure $8 \mathrm{D}-\mathrm{F}$ ). The alterations in equilibrium shown in preliminary studies (data not shown) could be caused by Cre-induced recombination in the inner ear, cerebellum or brain stem as shown in our previous report ${ }^{34}$. The spinning syndrome in mice results from alterations in the vestibular apparatus of the inner 
A

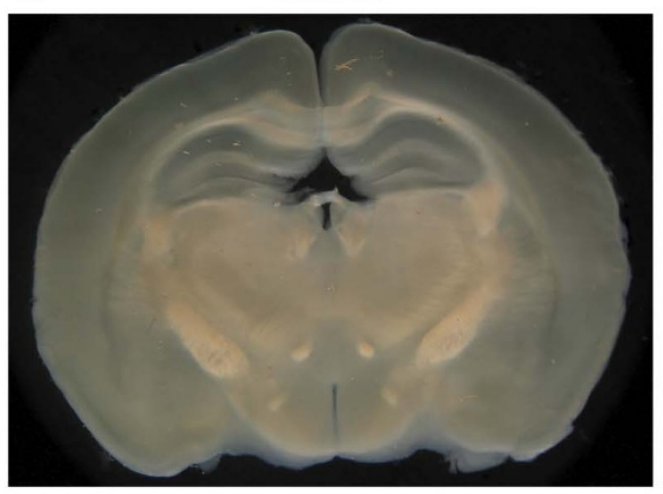

Pdx-Cre1; R26R

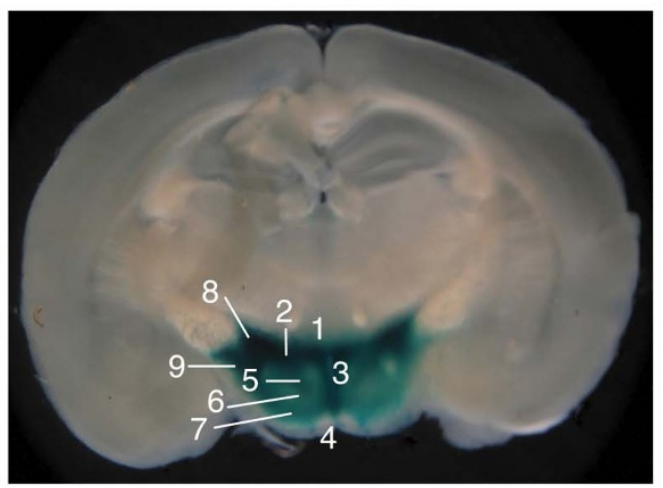

B
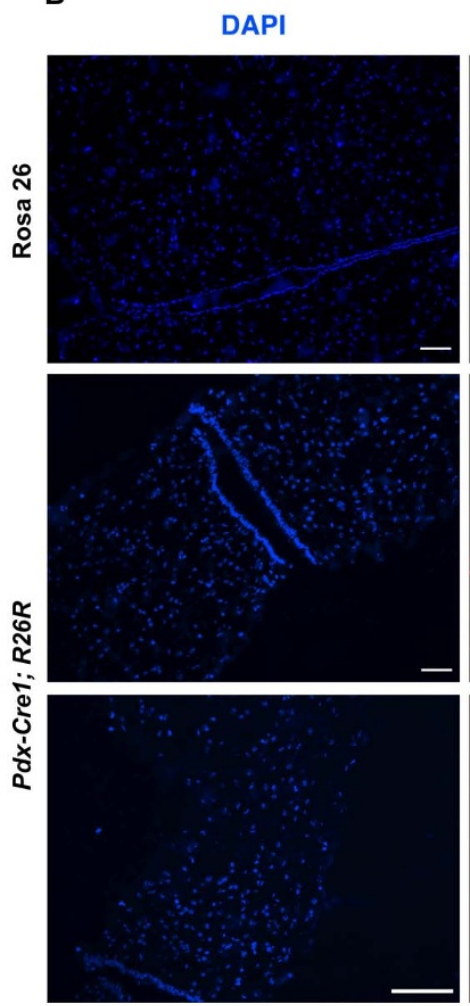

$\beta$-galactosidase
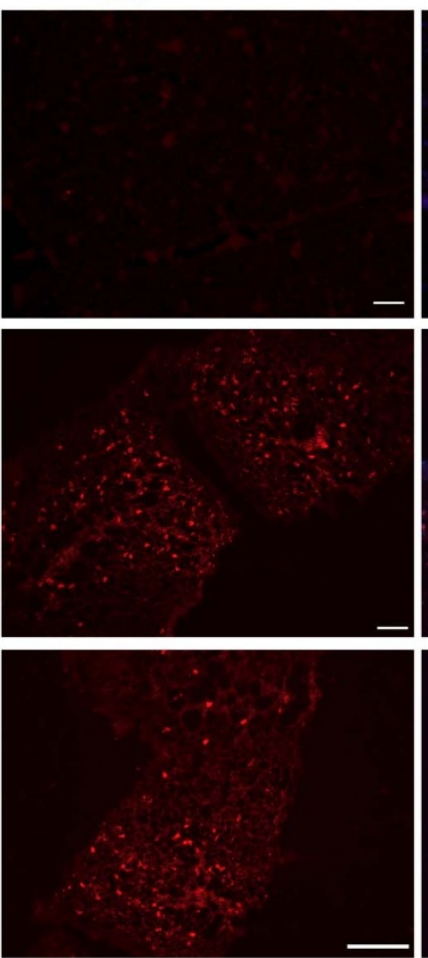
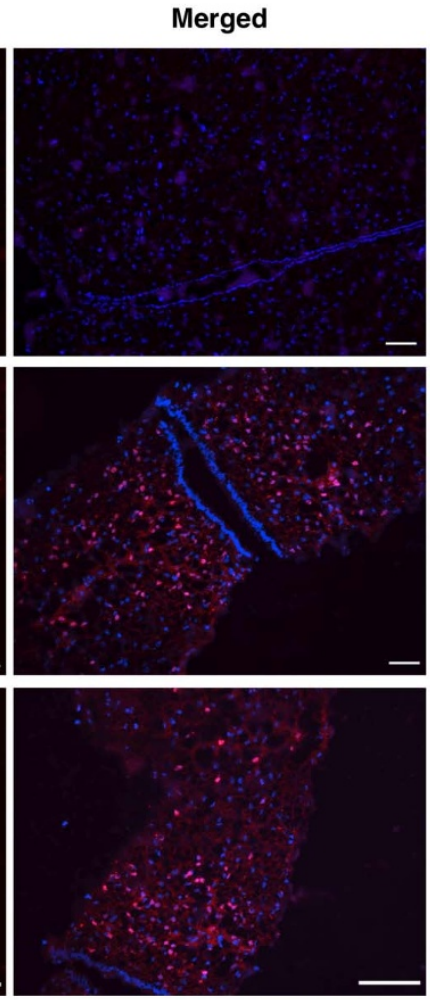

Figure 6 Expression of the Pdx1-Cre strain in the Brain. (A) X-gal activity (blue) on 1mm thick hypothalamus section of adult Rosa-26R and Pdx1$\mathrm{Cre}^{\text {early; }}$; Rosa-26R transgenic animals. $1=(\mathrm{Pe})$ periventricular hypothalamic nucleus, $2=(\mathrm{DM})$ dorsomedial nucleus of hypothalamus, $3=(3 \mathrm{~V}) 3 \mathrm{rd}$ ventricule, $4=(\mathrm{Arc})$ arcuate nucleus of hypothalamus, $5=(\mathrm{VMHDM})$ ventromedial hypothalamic nucleus, dorsomedial part, $6=(\mathrm{VMHC})$ ventromedial hypothalamic nucleus, central part, $7=(\mathrm{VMHVL})$ ventromedial hypothalamic nucleus ventrolateral part, $8=($ Subl $)$ subincertal nucleus, $9=(\mathrm{LH})$ lateral hypothalamic area. (B) Immunofluorescence staining for $\beta$-galactosidase (red) in Rosa-26R and Pdx1-Cre; Rosa-26R hypothalamic sections. Nuclei are counterstained with DAPI. Scale bars, $50 \mu \mathrm{m}$.

ear and a similar spinning phenotype has been described in mice with mutations in the protocadherin $15(\operatorname{Pcdh} 15)^{37}$. Future experiments could be designed to determine the extent to which $\mathrm{P} \beta \mathrm{cat}-\mathrm{KO}$ mice exhibit alterations in the vestibular component of the inner ear.

The current studies demonstrate that $\mathrm{P} \beta$ cat-KO mice were lean and resistant to weight gain induced by HFD compared to controls. These abnormalities were not explained by a decrease in food intake but instead from higher energy expenditure and metabolic rate due to augmented activity in unrestrained conditions. The enhanced energy expenditure observed in restrained conditions could also be explained in part by the favorable effects of chronic exercise after a short period of restraint ( 24 hour). The increased food intake in $\mathrm{P} \beta$ cat-KO mice led us to investigate the role of tissues involved in appetite control. To assess this, we first looked at Cre-mediated recombination in
Pdx1-Cre;R26R mice in the hypothalamus. The results of these experiments were recently published and strongly demonstrated that Pdx1-Cre induces recombination by X-gal activity on sagittal sections of the brain specifically in the ventral premammilary nucleus, arcuate nucleus, dorsomedial hypothalamus, suprachiasmatic nucleus, and medial preoptic area ${ }^{34}$. More importantly, Pdx1-Cre line causes recombination in orexin- and LepRb-expressing neuronal populations, a subset of hypothalamic neurons involved in energy and nutrient homeostasis ${ }^{34}$. This is particularly interesting because orexin neurons regulate feeding behavior, physical activity and circadian cycles. Therefore, it is conceivable that deletion of $\beta$-catenin in orexin could in part explain some of the abnormalities in feeding behavior and perhaps hyperactivity observed in $\mathrm{P} \beta$ cat-KO. Indeed, $\mathrm{P} \beta$ cat-KO mice displayed increased orexin expression in hypothalamus (data 
A

Before fat feeding

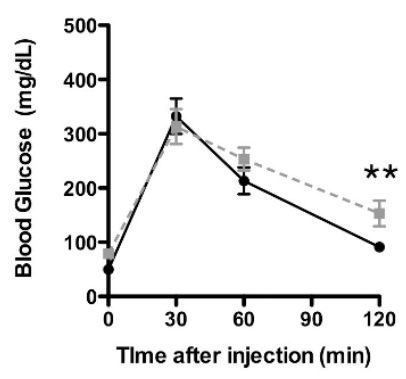

D

14 weeks

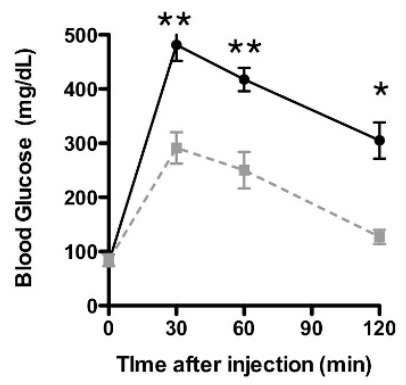

$\mathbf{F}$

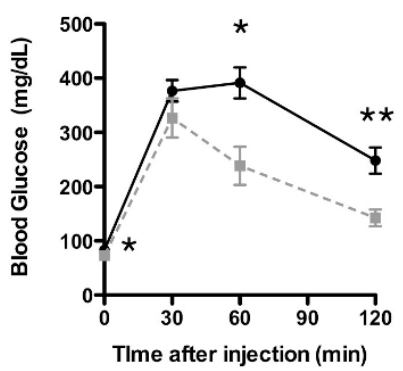

B

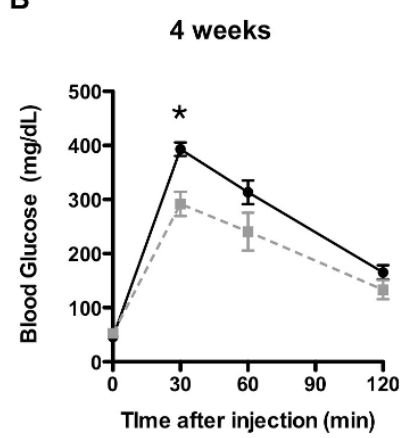

E

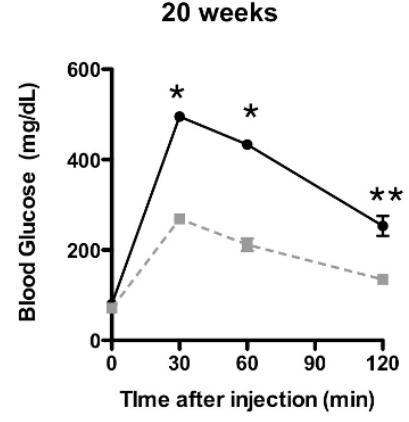

G

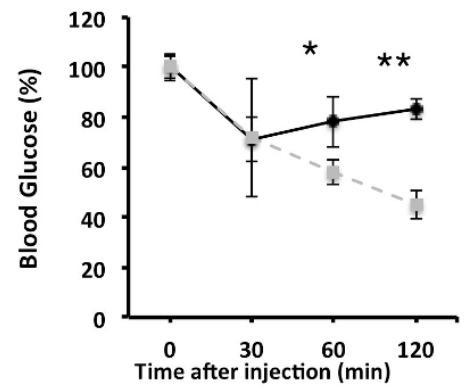

C

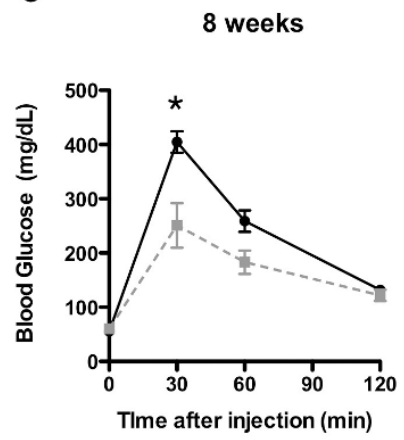

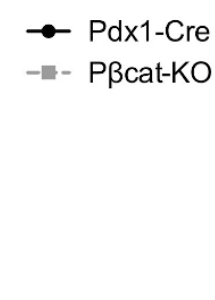

H

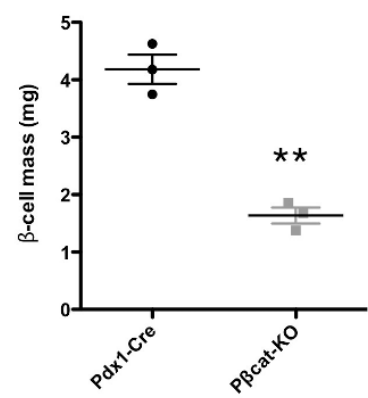

Figure 7 Resistance to diet induced obesity and insulin resistance in Pßcat-KO animals. (A) Intraperitoneal glucose tolerance test carried out after an overnight fasting on 8 weeks old males. The tests were then performed after 4 (B) 8 (C), 14 (D) and (E) 20 weeks on high fat diet (HFD). Oral glucose tolerance test $(\mathrm{F})$, insulin tolerance test $(\mathrm{G})$ and quantification of $\beta$-cell mass $(\mathrm{H})$ on control and $\beta$-catenin deleted males animals fed western diet for 20 weeks. Data are presented as mean \pm SEM from at least 5 mice per group. ${ }^{*} \mathrm{p} \leq 0.05,{ }^{* *} \mathrm{p} \leq 0.005$.

not shown). Future experiments will be designed to determine how $\beta$ catenin regulates orexin expression. The role of $\beta$-catenin in appetite control and motor activity could be tested in mice with deletion of $\beta$ catenin using Orexin-Cre mice ${ }^{38}$.

Current knowledge suggests that the $\mathrm{Wnt} / \beta$-catenin signaling pathway plays an important role in glucose homeostasis. How this signaling pathway alters different tissues to control glucose, insulin sensitivity, energy homeostasis and susceptibility to diabetes is not completely understood. Our study provides important insight into the mechanisms by which $\mathrm{Wnt} / \beta$-catenin signaling modulates glucose metabolism and energy expenditure. More importantly, this work sheds light into how TCF7L2 variants may regulate metabolism and susceptibility to type 2 diabetes. Future studies will be designed to elucidate how $\beta$-catenin modulates transcription in different tissues to regulate these physiological processes.

\section{Methods}

Breeding scheme and generation of $\beta$-catenin conditional knockout mice. Mice carrying a floxed allele of $\beta$-catenin $\left(\beta\right.$-cat ${ }^{\text {tox } /+}$ ) and $\beta$-catenin heterozygous mice ( $\beta$ $\left.\mathrm{cat}^{+/}\right)$have been described ${ }^{39}$. Conditional deletion of $\beta$-catenin in the pancreas was achieved by crossing these mice to Pdxl-cre ${ }^{33}$. The mating scheme was designed to generate Pdx1-Cre mice with one floxed allele and one deleted allele of $\beta$-catenin (Pdx1-Cre; $\beta$-cat ${ }^{\mathrm{flox} /}$ - further referred to as $\left.\mathrm{P} \beta \mathrm{catKO}\right)$. Pdx1-cre mice were used as controls for all the experiments. In another set of experiments, we designed a mating scheme to delete $\beta$-catenin using two floxed alleles within the same Pdx1-cre background. Male mice were used for these studies and were in a C57/B6 background, maintained on a normal light/dark cycle and genotyped by PCR as described ${ }^{39}$. For high fat feeding studies, 2 month old mice were fed chow containing $42 \%$ calories from fat (Harlan) for 20 weeks. Experiments were performed in males using littermates as controls. The Washington University School of Medicine and University of Michigan Animal Studies Committees approved all procedures.

Assessment of body weight, food intake, activity and energy expenditure. The animal size was determined by measuring body length from the nose to the rump. 
A

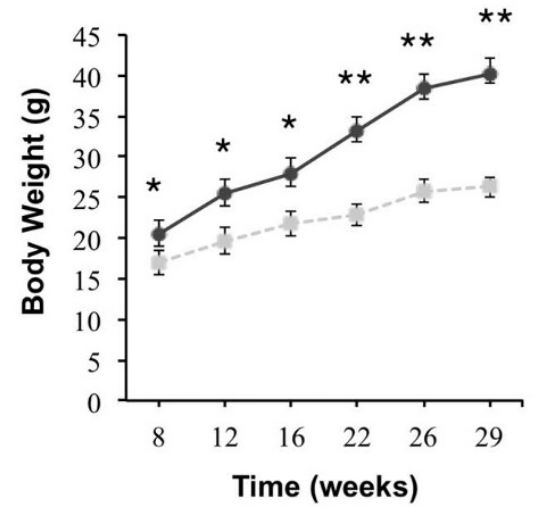

B

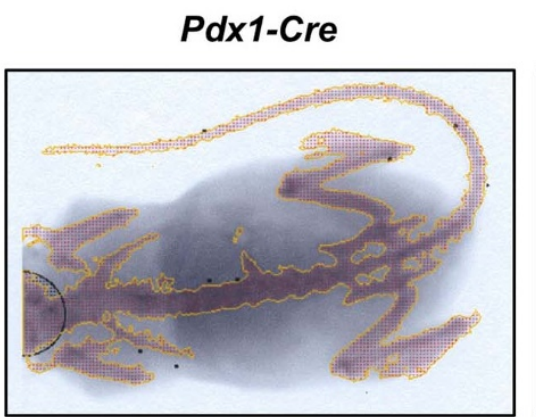

Pßcat-KO

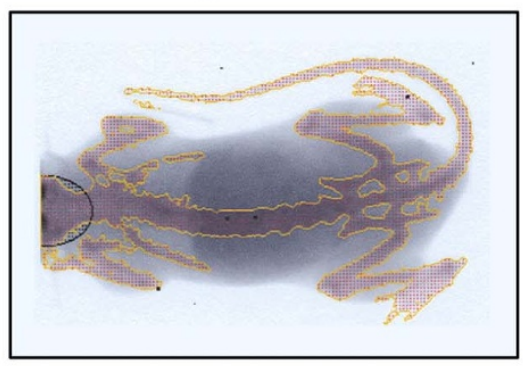

C

\begin{tabular}{|ccccc|}
\hline & Length $(\mathbf{c m})$ & BMD & Bone Area $\left(\mathbf{c m}^{2}\right)$ & $\%$ Fat \\
Pdx1-Cre & $10.90 \pm 0.11$ & $0.06 \pm 0.0006$ & $10.21 \pm 0.24$ & $32.83 \pm 3.18$ \\
Pßcat-KO & $9.43 \pm 0.05$ & $0.05 \pm 0.002$ & $9.48 \pm 0.42$ & $18.48 \pm 2.04$ \\
$t$-Test & 0.00001 & 0.14 & 0.19 & 0.01 \\
\hline
\end{tabular}
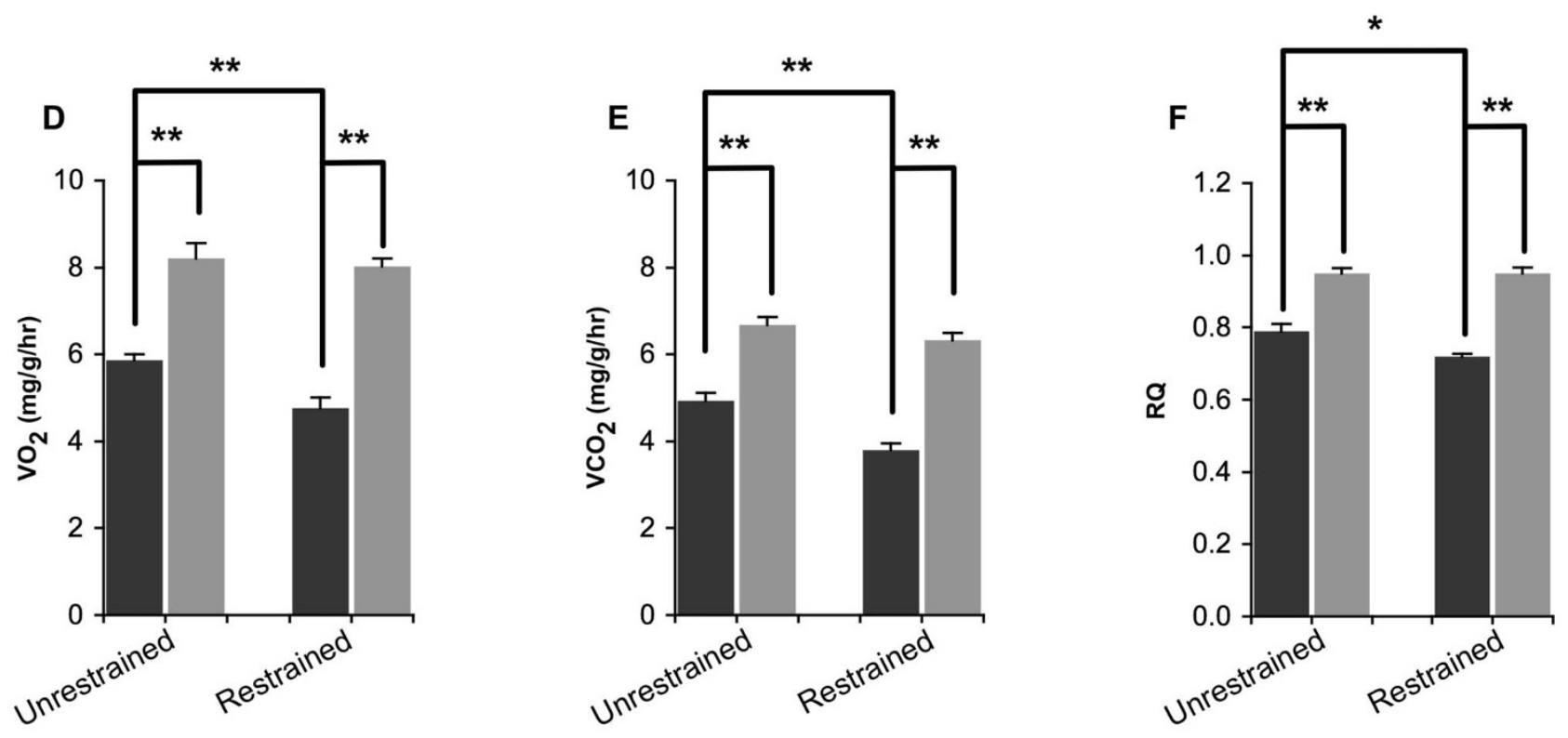

Pdx1-Cre

\section{$P \beta$ cat-KO}

Figure $8 \mid$ Pßcat-KO animals are resistant to diet induced weight gain and are still hyperactive. (A) Body weight evolution of control (black line) and $\beta$-catenin-deleted (grey line) animals on HFD. (B, C) Body fat content in Pdx1-Cre and Ps. $\beta$-cat KO after 20 weeks of fat diet chow that was determined by analysis of DEXA images. $\mathrm{O}_{2}$ consumption (D) $\mathrm{CO}_{2}$ production (E) and respiratory quotient (RQ) (F) measured in the same group of animals over $24 \mathrm{~h}$ period of time at the end of 20 weeks of fat feeding. Data are presented as mean \pm SEM for at least 5 animals per group. ${ }^{*} \mathrm{p} \leq 0.05, * * \mathrm{p} \leq 0.005$.

Food intake was calculated daily in single-housed animals for 7 days. For energy expenditure experiments, age and sex-matched animals were individually housed in Oxymax chambers (Columbus Instruments, Columbus, OH, USA) and were maintained for 24 hours in a 12 hours light/dark cycle with free access to food and water. Prior to recording the physiological parameters, all the mice were acclimatized to the Oxymax cages for 24 hours to minimize the changes in housing environment. Physical movements, $\mathrm{O}_{2}$ consumption, $\mathrm{CO}_{2}$ production, and respiratory quotient
(RQ) were measured using Oxymax software version 2.3. Data were collected every 60 minutes for each animal over a $24 \mathrm{~h}$ period of time. Physical activity and metabolic rate were averaged for the whole study period.

Dual-energy X-ray absorptiometry (Dexa) scan analysis. Body composition was assessed using a small animal densitometer (Lunar PIXIMUS DEXA, GE Systems $)^{40}$. Mice were anesthetized and scanned, and the bone mineral density, 
and total body fat composition were recorded using an analysis program provided by the manufacturer.

Metabolic studies. Blood glucose levels were determined from blood obtained from the tail vein after an overnight fast. Glucose was measured on whole blood sample using an AccuChek II glucometer (Roche Diagnostics). Glucose tolerance tests were performed on overnight fasted animals by injecting glucose $(2 \mathrm{mg} / \mathrm{g})$ intraperitoneally as previously described ${ }^{41,42}$. Plasma insulin levels were measured on $5 \mu \mathrm{l}$ aliquots using rat insulin ELISA kit (ALPCO Diagnostics, Salem, NH, USA). For insulin-tolerance testing, 6 hours fasted animals received an injection of human insulin intraperitoneally ( $0.5 \mathrm{U} / \mathrm{kg}$ of body weight). Blood glucose levels were determined just before the injections and then at the indicated times.

Lipids measurement. Serum samples from control and P $\beta$ catKO animals were assayed for cholesterol, triglycerides, and free fatty acids as described ${ }^{43}$. Stool samples were collected and fecal fat content was analyzed quantitatively by organic extraction with heptane:diethylether:ethanol $(1: 1: 1 \mathrm{vol} / \mathrm{vol})$ and then twice with heptane:diethylether:ethanol:water $(1: 1: 1: 1)^{44,45}$. Lipids were measured gravimetrically after the organic extractions and solvent evaporation.

Immunostaining and islet morphometry. Freshly isolated adult pancreata were fixed overnight in formalin and subsequently embedded in paraffin using standard techniques. The following primary antibodies were added overnight to the sections: anti rabbit $\beta$-catenin (1:1000; Sigma, St-Louis, Mo, USA), anti guinea-pig Insulin (1:800; Dako, Carpinteria, CA, USA), anti rabbit Amylase (1:500; Sigma, St-Louis, Mo, USA), anti mouse Amylase (1:200; Santa Cruz, Santa Cruz, CA, USA), anti rabbit Glucagon (1:700; Chemicon, Billerica, MA, USA), anti rabbit Somatostatin (1:200; Dako, Carpinteria, CA, USA), anti rabbit Pancreatic Polypeptide (1:40; Chemicon, Billerica, MA, USA), anti rabbit Ki67 (1:200; Novocastra, Buffalo Grove, IL, USA), anti rabbit cleaved caspase-3 (1:50; Cell signaling, Boston, MA, USA). Sections were then incubated for 4 hours with the appropriate secondary antibodies (Jackson Immunoresearch, West Grove, PA, USA). Nuclei were counterstained with 4', 6-Diamidino-2-phenylindole (DAPI; Vector Laboratories, Burlingame, CA, USA). Images were obtained using a Leica microscope DM4000B with a Leica DFC 350FX camera and subsequently processed with Leica Application Suite software V.2.5R1. For proliferation assays, Ki67 staining was performed to identify cells in the S-phase of the cell cycle. $\beta$-cell proliferation was calculated by dividing Ki67-positive $\beta$-cells by the total number of counted $\beta$-cells and expressed as percentage. Apoptotic rates were determined by cleaved-caspase 3 staining. $\beta$-cell apoptosis was calculated by dividing the number of cleaved-caspase 3 positive $\beta$-cells by the total number of $\beta$-cells and expressed as percentage. At least 2000 insulin-positive cells were counted per animal. Islet morphometry was performed on pancreata from $\mathrm{P} \beta$ catKO and Pdx1-Cre animals. The $\beta$-cell mass was performed in 5 insulin-stained pancreas sections using NIH ImageJ software (v1.44m freely available at http://rsb.info.nih. gov/ij/ index.html $)^{46}$ as previously described ${ }^{41}$.

Statistical analysis. All values are expressed as mean \pm standard error of the mean. Statistical analyses were conducted using a non-parametric Mann-Whitney test. Differences were considered statistically significant with a $\mathrm{p}$-value $\leq 0.05$.

1. Talchai, C., Lin, H. V., Kitamura, T. \& Accili, D. Genetic and biochemical pathways of beta-cell failure in type 2 diabetes. Diabetes, obesity \& metabolism 11 Suppl 4, 38-45 (2009).

2. Chang-Chen, K., Mullur, R. \& Bernal-Mizrachi, E. beta-cell failure as a complication of diabetes. Reviews in Endocrine and Metabolic Disorders 9, 329-343 (2008)

3. Prokopenko, I., McCarthy, M. I. \& Lindgren, C. M. Type 2 diabetes: new genes, new understanding. Trends in genetics : TIG 24, 613-621 (2008).

4. Florez, J. C. Clinical review: the genetics of type 2 diabetes: a realistic appraisal in 2008. The Journal of clinical endocrinology and metabolism 93, 4633-4642 (2008).

5. Florez, J. C. Newly identified loci highlight beta cell dysfunction as a key cause of type 2 diabetes: where are the insulin resistance genes? Diabetologia 51, $1100-1110$ (2008).

6. Sladek, R. et al. A genome-wide association study identifies novel risk loci for type 2 diabetes. Nature 445, 881-885 (2007)

7. van Hoek, M. et al. Predicting type 2 diabetes based on polymorphisms from genome-wide association studies: a population-based study. Diabetes 57, 3122-3128 (2008).

8. Zeggini, E. et al. Meta-analysis of genome-wide association data and large-scale replication identifies additional susceptibility loci for type 2 diabetes. Nature genetics 40, 638-645 (2008).

9. Lyssenko, V. et al. Clinical risk factors, DNA variants, and the development of type 2 diabetes. The New England journal of medicine 359, 2220-2232 (2008).

10. Liu, Z. \& Habener, J. F. Wnt signaling in pancreatic islets. Adv Exp Med Biol 654, 391-419 (2010).

11. Grant, S. F. A. et al. Variant of transcription factor 7-like 2 (TCF7L2) gene confers risk of type 2 diabetes. Nature genetics 38, 320-323 (2006).

12. Jin, T. The WNT signalling pathway and diabetes mellitus. Diabetologia $\mathbf{5 1}$, 1771-1780 (2008)

13. Gloyn, A. L., Braun, M. \& Rorsman, P. Type 2 diabetes susceptibility gene TCF7L2 and its role in beta-cell function. Diabetes 58, 800-802 (2009).
14. Bonetti, S. et al. Variants and haplotypes of TCF7L2 are associated with $\beta$-cell function in patients with newly diagnosed type 2 diabetes: the Verona Newly Diagnosed Type 2 Diabetes Study (VNDS) 1. The Journal of clinical endocrinology and metabolism 96, E389-393 (2011).

15. Liu, Z. \& Habener, J. F. Glucagon-like peptide-1 activation of TCF7L2-dependent Wnt signaling enhances pancreatic beta cell proliferation. The Journal of biological chemistry 283, 8723-8735 (2008).

16. Shu, L. et al. Transcription factor 7-like 2 regulates beta-cell survival and function in human pancreatic islets. Diabetes 57, 645-653 (2008).

17. Dessimoz, J., Bonnard, C., Huelsken, J. \& Grapin-Botton, A. Pancreas-Specific Deletion of beta-Catenin Reveals Wnt-Dependent and Wnt-Independent Functions during Development. Current biology : CB 15, 1677-1683 (2005).

18. Rulifson, I. C. et al. Wnt signaling regulates pancreatic beta cell proliferation. Proceedings of the National Academy of Sciences of the United States of America 104, 6247-6252 (2007)

19. MacDonald, B. T., Tamai, K. \& He, X. Wnt/beta-catenin signaling: components, mechanisms, and diseases. Dev Cell 17, 9-26 (2009).

20. Cadigan, K. M. Wnt-beta-catenin signaling. Curr Biol 18, R943-947 (2008)

21. Nelson, W. J. \& Nusse, R. Convergence of Wnt, beta-catenin, and cadherin pathways. Science (New York, NY) 303, 1483-1487 (2004).

22. Nusse, R. Wnt signaling in disease and in development. Cell Res 15, 28-32 (2005)

23. Gooding, J. M., Yap, K. L. \& Ikura, M. The cadherin-catenin complex as a focal point of cell adhesion and signalling: new insights from three-dimensional structures. Bioessays 26, 497-511 (2004).

24. Welters, H. J. \& Kulkarni, R. N. Wnt signaling: relevance to beta-cell biology and diabetes. Trends in endocrinology and metabolism: TEM 19, 349-355 (2008).

25. Dabernat, S. et al. Lack of beta-catenin in early life induces abnormal glucose homeostasis in mice. Diabetologia 52, 1608-1617 (2009).

26. Murtaugh, L., Law, A., Dor, Y. \& Melton, D. \{beta\}-Catenin is essential for pancreatic acinar but not islet development. Development (Cambridge, England) 132, 4663-4674 (2005).

27. Papadopoulou, S. \& Edlund, H. Attenuated Wnt signaling perturbs pancreatic growth but not pancreatic function. Diabetes 54, 2844-2851 (2005).

28. Heiser, P. W., Lau, J., Taketo, M. M., Herrera, P. L. \& Hebrok, M. Stabilization of beta-catenin impacts pancreas growth. Development (Cambridge, England) 133, 2023-2032 (2006).

29. Wells, J. M. et al. Wnt/beta-catenin signaling is required for development of the exocrine pancreas. BMC Dev Biol 7, 4 (2007).

30. Heller, R. et al. Expression patterns of Wnts, Frizzleds, sFRPs, and misexpression in transgenic mice suggesting a role for Wnts in pancreas and foregut pattern formation. Developmental dynamics : an official publication of the American Association of Anatomists 225, 260-270 (2002).

31. Fujino, T. et al. Low-density lipoprotein receptor-related protein 5 (LRP5) is essential for normal cholesterol metabolism and glucose-induced insulin secretion. Proc Natl Acad Sci U S A 100, 229-234 (2003).

32. Ahlgren, U., Jonsson, J. \& Edlund, H. The morphogenesis of the pancreatic mesenchyme is uncoupled from that of the pancreatic epithelium in IPF1/PDX1deficient mice. Development (Cambridge, England) 122, 1409-1416 (1996).

33. Gu, G., Dubauskaite, J. \& Melton, D. Direct evidence for the pancreatic lineage: NGN3 + cells are islet progenitors and are distinct from duct progenitors. Development (Cambridge, England) 129, 2447-2457 (2002).

34. Wicksteed, B. et al. Conditional gene targeting in mouse pancreatic B-Cells: analysis of ectopic Cre transgene expression in the brain. Diabetes 59, 3090-3098 (2010).

35. Soriano, P. Generalized lacZ expression with the ROSA26 Cre reporter strain. Nature genetics 21, 70-71 (1999).

36. Herrera, P. Adult insulin- and glucagon-producing cells differentiate from two independent cell lineages. Development (Cambridge, England) 127, 2317-2322 (2000).

37. Alagramam, K. N. et al. The mouse Ames waltzer hearing-loss mutant is caused by mutation of Pcdh15, a novel protocadherin gene. Nature genetics 27, 99-102 (2001).

38. Matsuki, T. et al. Selective loss of GABA(B) receptors in orexin-producing neurons results in disrupted sleep/wakefulness architecture. Proceedings of the National Academy of Sciences of the United States of America 106, 4459-4464 (2009).

39. Brault, V. et al. Inactivation of the beta-catenin gene by Wnt1-Cre-mediated deletion results in dramatic brain malformation and failure of craniofacial development. Development (Cambridge, England) 128, 1253-1264 (2001).

40. Bernal-Mizrachi, C. et al. Respiratory uncoupling lowers blood pressure through a leptin-dependent mechanism in genetically obese mice. Arteriosclerosis, thrombosis, and vascular biology 22, 961-968 (2002).

41. Bernal-Mizrachi, E., Wen, W., Stahlhut, S., Welling, C. \& Permutt, M. Islet beta cell expression of constitutively active Akt1/PKB alpha induces striking hypertrophy, hyperplasia, and hyperinsulinemia. The Journal of clinical investigation 108, 1631-1638 (2001).

42. Fatrai, S. et al. Akt induces beta-cell proliferation by regulating cyclin D1, cyclin D2, and p21 levels and cyclin-dependent kinase-4 activity. Diabetes 55, 318-325 (2006).

43. Towler, D. A., Bidder, M., Latifi, T., Coleman, T. \& Semenkovich, C. F. Dietinduced diabetes activates an osteogenic gene regulatory program in the aortas of 
low density lipoprotein receptor-deficient mice. The Journal of biological chemistry 273, 30427-30434 (1998).

44. Jeejeebhoy, K. N., Ahmad, S. \& Kozak, G. Determination of fecal fats containing both medium and long chain triglycerides and fatty acids. Clin Biochem 3, 157-163 (1970).

45. Ma, T. et al. Defective dietary fat processing in transgenic mice lacking aquaporin1 water channels. Am J Physiol Cell Physiol 280, C126-134 (2001).

46. Girish, V. \& Vijayalakshmi, A. Affordable image analysis using NIH Image/ ImageJ. Indian J Cancer 41, 47 (2004).

\section{Acknowledgements}

This work was supported by a National Institutes of Health Grant RO1-DK-073716-01 and 5R01DK084236-02 (to E.B.-M.)

The authors acknowledge support from the Radioimmunoassay, Morphology Core from the Washington University Diabetes Research and Training Center (DRTC).

The authors also thank the Morphology Core from Washington University Digestive Diseases Research Core Center (DDRCC) for histology sections. No potential conflicts of interest relevant to this article were reported. The authors thank M. Alan Permutt

(Washington University School of Medicine, Saint-Louis, MO) for helpful comments.

\section{Authors contributions}

EL performed the experiments, analyzed the data, and wrote the manuscript and prepared the figures. AG, AW, DB, JC handled the mouse breeding colony and genotyping. DO helped with some immunohistochemistry. MM reviewed the manuscript. CCM helped with the statistical analysis, videotaping. EBM wrote and reviewed the paper. All authors reviewed the manuscript.

\section{Additional information}

Supplementary information accompanies this paper at http://www.nature.com/ scientificreports

Competing financial interests: The authors declare no competing financial interests.

License: This work is licensed under a Creative Commons

Attribution-NonCommercial-NoDerivative Works 3.0 Unported License. To view a copy of this license, visit http://creativecommons.org/licenses/by-nc-nd/3.0/

How to cite this article: Elghazi, L. et al. Importance of $\beta$-Catenin in glucose and energy homeostasis. Sci. Rep. 2, 693; DOI:10.1038/srep00693 (2012). 